\title{
Claudio DONDI
}

\section{AFTER THE EDEN GENOA 2018 CONFERENCE: SUGGESTING A NEW RELEVANCE FRONTEER}

The EDEN Annual Conference in Genoa was an enriching event, both because the presentations which were stimulating as usual, and, even more importantly, because it allowed to review the state of an always vibrant community of people who never give up to devote their academic and professional lives to what they believe is the future of education and lifelong learning.

Having spent a lot of my professional life within the EDEN community, I fully sympathise with this attitude, but, having spent the last four years in the world of what we may call "mainstream education", I have to recognise that "our" view of the world of education is still considered extravagant, if not openly heretic, by the majority of education authorities, teachers, parents and probably also students.

The fact is not that the "mainstream education" does not see the challenges and the change that is occurring in society, but the key strategy to face change is considered to be the updating of taught contents and the standardisation of learning outcomes, while using more or less the same teaching, evaluation and organisation processes, if necessary supported by technological devices.

The questions of learning methods, central role of learners, open-endedness of learning programmes, shift in the assessment and credentialisation methods are frequent in the research agenda and in the international policy debate on education innovation, but, when it comes to actual decision making, the focus is on contents of curriculum, qualifications, standard testing, accreditation, ranking and funding.

Even the School Resource Review conducted by OECD does not explicitly consider the role of open, distance, eLearning and methodological/technological innovation in the "resources review of school systems".

Where is the problem? Are we not able to explain what we have been seeing and doing for thirty years or is the "mainstream education" unable to understand the need for a deep change?

The resistance to change of education systems has been analysed several times and identified as one of the key obstacles to the widespread adoption of innovation, but my point here is that our community also risks to be "stuck in the middle" as the title of a brilliant paper in the conference was saying. We, "the Innovators", see a new development in technology or society and warmly embrace it to explore its potential in education systems, we create sub-communities of "specialists of the new", launch some EU projects on the subject and predict that education will never be the same again after the generalized adoption of this new development. This might be true in principle, but the fact is that generalized adoption in mainstream education never took place: most of the predictions we were reading and writing twenty years ago look very naive when we read them again now, when picking up our children from school.

The fact that technology devices are part of every day's life and are present in education establishments is not the result of "our" battles for innovation, but the consequence of exogenous developments in a "digital world"; education does not use but a very small part of ICT potential for "educational change" purposes. Out of the institutional education systems quick evolution of learning habits is easy to observe, but should we simply accept that school and university are deemed to become obsolete because they are unable to change their key processes and to cope with major change? 
I believe that we should not accept obsolescence of education systems and rather try to organise evidence and support to produce significant change at system level: the impact of technology in the world of learning is too important to be left in the hands of education authorities, but also to be left to market forces without a "public good" inspiration, guaranteeing equity and quality together with innovation.

In my view EDEN should pick up the role of showing how the different societal challenges that affect education can be better addressed when the full range of innovations available is considered, how the many apparent and "classic" dichotomies that define the scope of education policies (e.g. excellence vs equity, specialisation vs critical thinking, standards vs individual talent, open access vs remuneration of investment, regulated vs. informal, etc) can all be rethought when a full picture of innovation in education is built and an "out-of-the-box" perspective is adopted, focused on what society expects from education rather than what has always been done.

During the Genoa Conference it was clear that the innovators community continues to explore new developments, shows vitalism and dedication to its cause, but I perceived a risk of fragmentation on different separated priorities and self-referential syndrome this year, that made me appear negative to some when I presented the Conference general report in the last plenary.

Perceiving and signalling a risk is, in my view, the most positive contribution one could do; in any case to clarify thoughts in the following paragraphs and to make some "positive" proposals.

- The Conference plenaries and several parallel sessions contained, coherently with the EDEN tradition, very stimulating and provoking statements on the change that is affecting the world and would probably affect education in the near future; unfortunately almost all speakers were in substantial agreement with this idea, very few voices were challenging the main thesis (that education will go through a very substantial change in a matter of few years).

- Several parallel sessions were presenting, more modestly, the results of projects undertaken some time ago to explore the potential of alternative ways to organise, assess, document learning process and achievements: they were interesting, but apparently satisfied with their small scale of operation and modest relevance at system level.

- The issue of "mainstreaming innovation" in view of addressing the main challenges of society was only partially addressed in one parallel session, that rightly pointed out the gap between a project-based innovation "reserve" -typically represented by ERASMUS PLUS and HORIZON 2020- and a "business-as-usual attitude" by decision making bodies in the world of education. The inefficiency of small projects to vehicle major innovative developments was stated, but new instruments are not easily available.

- A certain fragmentation of the participants groups into "thematic parties", sometimes in opposition to one another, was for me a curious new development, recalling the well-known phenomenon of stratification of innovation waves, through which innovators of a previous generation become conservative towards innovators of a more recent generation; in this way the possibility of synergies and a system view is lost through this juxtaposition.

Loosing a sense of direction and reproducing the same dynamics of multiple starts without a substantial impact on the education systems appeared as two relevant risks. The paradox is that within the EDEN community many people are gathered, who strive for good education and understand how technology and methodological innovation can help facing new challenges, but they are, as a community, only moderately effective in influencing policy and mainstream education practice. 
In order to improve this situation, and to put the professional community in the conditions to play an even more active role in promoting education innovation - a role that I believe it deserves - my recommendations are the following:

- Systematically invite "mainstream education" decision makers and stakeholders to intervene in major European events, listen and argue with us if they are not convinced by our thesis: understanding their points and trying to challenge them will help us to find our way into mainstream.

- Try to build, with the precious help of the EDEN Fellows and in collaboration with the competent international institutions (EIT, ILO, IPTS), a system view in which older and newer innovation ideas concur to define a new vision of how education and lifelong learning should look like to face the challenges of our society. This system view might become a reference to link different groups of education innovators and a visible target for public policies to come. The centrality of learner and the competence to learn in a self-regulated way should be the hub-concept on which to articulate the set of innovative ideas and solutions that technology can help to make possible for all, inclusive within the formal education world.

- Establish a better connection between "the visionnaires" and the crowd of "grassroots innovators" in the EDEN community, to make the first group more realistic and the second more ambitious: at the moment they seem to play on different grounds, while their synergy may reveal to be very effective to assess the potential of innovative ideas and spread them across the education systems in a combined bottom-up and top-down dynamics.

- Advocate for a different generation of (EU and national) policy instruments able to collect the results of similar/complementary pilot projects and to upscale them into widespread practice in education systems.

I am convinced that these concrete steps would contribute to make relevance and impact the core criteria for success in the next years, and I propose them for internal debate within our community. 